\title{
Oxidative Stress Level in Onco-Surgical Treatment Dynamics at Patients with Malignant Colo-Rectal Tumors
}

\author{
MARIA IULIANA GRUIA ${ }^{1 \#, ~ S E R B A N ~ M A R I N E S C U ~}{ }^{1 \#, ~ D R A G O S ~ P R E D E S C U ~}{ }^{2 \#, ~}$ \\ GEORGE JINESC ${ }^{2 * \#}$, BOGDAN SOCEA ${ }^{3}$, ION GRUIA ${ }^{4 \#}$ \\ ${ }^{1}$ Institute of Oncology "Prof. dr. Al. Trestioreanu", 252 Soseaua Fundeni, 022328, Bucharest, Romania \\ ${ }^{2}$ University of Medicine and Pharmacy Carol Davila Bucharest, 37 Dionisie Lupu Str., 020021, Bucharest, Romania \\ ${ }^{3}$ Clinic of Surgery, St.Pantelimon Hospital, 340-342 Soseaua Pantelimon, 021661, Bucharest, Romania \\ ${ }^{4}$ University of Bucharest -Faculty of Physics, 405 Atomistilor Str., Magurele, Romania
}

\begin{abstract}
Colorectal cancer (CRC) is one of the most common human malignancies, affecting one of 20 persons in areas with high socio-economic standard. In Romania, the frequency of colorectal cancer is growing rapidly placing the country among countries with an average incidence of the disease. There are some etiologic factors involved and treatment of disease is carried out after proper staging. Biochemical mechanisms underlying malignant transformation in colorectal cancer are not all fully understood, therefore our work trying to enter in the path of oxygen metabolism at patients surgically treated. The aim of the study is to follow the production of active metabolites of oxygen, in the dynamics of the surgical procedure, and how the endogenous natural protection systems are activated, following the invasive procedure. Oxidative stress biochemistry assays, realized before and after surgical excision showed a direct relationship between the production of reactive oxygen species and the presence of tumor, without being able to distinguish exactly if malignant tissue is able to induce oxidative stress, or the latter occurs due to neoplastic changes. Based on the results we can say with certainty that the reactive oxygen species ROS primary attack occurs in the lipids, and then the proteins, following activation of endogenous antioxidant defence.
\end{abstract}

Keywords: reactive oxygen species, oxidative stress, endogenous antioxidant defence, plasma malondialdehyde marker, thyol group, ceruloplasmin, colorectal cancer

\section{Intoduction}

Colorectal cancer (CRC) is one of the most prevalent neoplasms and the third leading cause of cancer death. Regarding the incidence of neoplasms in women in general, CRC ranks fourth, after breast, cervical and lung cancer. Cancer mortality in women is attributed, in order of frequency: breast, lung, colorectal and cervical cancers. In men's incidence, CRC comes after lung and prostate cancer and occupies the same position, third, in mortality $(1,2)$. Overall CRC incidence data shows a modest decrease since the 1980s in industrialized countries and a slow but steady growth in poorly developed countries (eg in the USA since 1998 the incidence of CRC has decreased by about 2.2\% per year). This decrease is essentially attributed to the CRC screening techniques.

Interestingly, the variety between nations in rectal malignancy rate is lesser when contrasted with the frequency of colorectal cancer $(3,4)$.

From an etiological point of view, CRC represents an entity induced on the one hand by environmental factors and on the other hand by genetic factors or, not rarely, by their combination (57). From the genetic perspective, based on the causes involved in the emergence of CRC, there are three major types: sporadic CRC (60-70\%), family CRC (30-40\%), hereditary CRC (genetic diseases 4-6\%).

*email: gjinescu@yahoo.com

\# Authors with equal contributions. 
CRC evolution has a slow progression (from the onset until it becomes clinically detectable it has a history of about 1.5-2 years). Clinical manifestations of CRC are frequently masked and the paraclinic diagnosis are by consequence delayed. Quite often, the metastasis and the discharge of the tumoral cells in blood stream has by consequence a very poor result despite a corect therapeutical approach.

This characteristic - spreading tumor tissue - is based on a number of specific and special properties of the cancer cell, existing in its own biological arsenal. Particularly for colorectal cancer but also for other histopathological types of cancer, this „bad and uncontrollable" cellular behavior has been interpreted as a consequence of a process name „epithelial-mesenchymal transition (EMT)" (7-10).

By comparison with other types of cancer, colorectal cancer can be used like decent system and applicable model to investigate and study the process of carcinogenetic differentiation and the molecular changes responsible for tumor evolution and development. But one thing is clear: these evolutions are the consequence of the appearance of cellular genomic alterations, which can accumulate over time, and which can affect the normal control of epithelial development as well as the cell differentiation process to. For this, a series of works and research have been proposed to study, gather and draw conclusions about the etiology of the appearance and development of adenomatous polyps at the colorectal site, as well as the mechanisms that may or may not lead to the development of cancer. The results allowed to identify numerous intracellular mechanisms whose functioning is altered by the induction of some modifications in genetic material, due to environmental factors, including dietary habits, and on the other hand by genetic factors or, not rarely, by their combination (11-14).

However, in sporadic CRC, the most encountred type, we find two mechanisms of genomic instability: i) chromosomal instability (CIN), consequence of alteration of genetic material, resulting in inactivation of tumor suppressor genes (ex. TP 53, APC) or activation of oncogenes (Ki-ras) in about $80-98 \%$ of cases; ii) microsatellite instability (MSI), without knowing the genes involved (10\% of cases).

A very good example, of an otherwise physiological process up to a point, and which will cause genomic alterations is that of reactive oxygen species (ROS). ROS are dynamic chemically molecules created by partial processes in oxygen reduction in cell (15-17). For this moment it is clearly known that ROS are involved at the cellular level in a series of physiological processes but, beyond a certain moment which is difficult to determine exactly, it drifts towards to pathological part and can follow the path of developing a malignancy. Very interesting was the finding that tumor cells seem to thrive at extreme variations in oxidative stress levels when compared to non-cancer tissue. A series of works invoke, as an example of the etiopathogenic importance in tumor development, the increased level of ROS in cancers of the pancreas, breast, colon, lung, prostate and more others (17-20). It rise, naturally, the question why, by which mechanism and how ROS contributes to carcinogenesis process? It seems that ROS can affect DNA, with the appearance of mutations in the genetic material, having as consequence the initiation of the irreversible process of oncogenesis. The genetic instability of ROS is the result of single strand breaks produced by oxidation of purines and pyrimidines, with the appearance of some alkali labile sites. This oxidative mechanism has an effect of altering the genetic material with the appearance of mutations, which are associated with the modification of GC base pairs. These mutations of GC base are mainly due to the substitution of base pairs and less often to deletions and insertions $(21,22)$. Numerous other mechanisms are described in which ROS play an extremely important role such as regulating expression of genes associated with tumor angiogenesis, cell growth and survival/apoptosis, tumor aggression and ability to metastasize by activating transcription factors including activator protein-1 (AP-1), nuclear factor- $\kappa \mathrm{B}(\mathrm{NF}-\kappa \mathrm{B})$, and hypoxia inducible factor-1 (HIF-1 $\alpha)(22-24)$. In an attempt to discover new therapeutic alternatives, the ability of ROS to trigger the process of apoptosis in tumor cells, seems at least at this moment an interesting solution. The identification of the action mechanism for various oncological therapies has allowed the discovery that, among other ways of oncoinhibition, the occurrence of ROS is not a negligible process. Furthermore, the administration of antioxidants during chemotherapy treatments has led to a decrease 
in therapeutic benefit, proving in addition, if necessary, the role of ROS in efficacy and response to oncological therapy.

The aim of the study is to identify the presence of tumor-induced oxidative stress, the effect of surgery on it and the role of antioxidants in the dynamics of the surgery.

\section{Materials and methods}

A total of 90 patients with malignant colorectal tumors, hospitalized in the Surgical Clinic of Bucharest Institute of Oncology in the period march - may 2015, were investigated. Patients were included in the study after signing their consent form, approved by the ethics committee of the Institute. The committee reviewed and approved the clinical trial conduct by decision 83 / 02.04.2015.

\section{Biochemical parameters investigated}

-Determination of malondialdehyde (MDA) - marker of lipid peroxidation MDA the end product of lipid peroxidation was determined by the thiobarbituric assay. Although lipid peroxidation of biological samples can be assessed through various physical and chemical methods, one of these is based on measuring MDA endoperoxides formed during the final phase oxidation of polyunsaturated fatty acids and is the simplest and most widely used. The serum MDA is a weak acid , unstable, highly reactive with TBA (thiobarbituric acid). The resulting red product has an absorption maximum at 532 $\mathrm{nm}$.

Although controversial, the method was widely used. Studying the specific extinctions at $532 \mathrm{~nm}$ of carbonyl compounds resulting from oxidative degradation of lipid hydroperoxide can be considered without fail that the absorption at $532 \mathrm{~nm}$ is due to the complex TBA - MDA; normal range: $0-4$ $\mu \mathrm{mol} / 100 \mathrm{~mL}$ serum

\section{-Assay of ceruloplasmin (CP)}

The physiological role of ceruloplasmin is complex and intensely studied. These include:

- transporting copper ions

- oxidation of organic amines

- oxidation of Fe 2+ to Fe 3+ by transferrin and ferritin his release

- antioxidant activity against lipid peroxidation

- modulating endogenous inflammatory response

- stimulating cell proliferation and angiogenesis

Ceruloplasmin is an acute phase protein which response amplitude is intermediate than other acute phase proteins, its levels increase 2-3 times in inflammation, pregnancy, injuries and surgeries

Catalytic oxidation of $\mathrm{Fe} 2+$ and $\mathrm{Fe} 2+$ containing complexes is called feroxidase activity. There are describes several methods for determining this activity of ceruloplasmin. We have used the method of Ravin (25) done by the reaction with p-phenylene diamine in acetic acid-acetate buffer.

The amount of enzyme which converts 1 micromol of substrate per minute is defined as 1 unit of ceruloplasmin; normal values are between 80- 120 U.I ceruloplasmin.

-Determination of albuminic thiol groups (-SH)

The determination was made by the method Albini, using DTNB (5,5'-Dithiobis-2-Nitrobenzoic Acid).

Thiol groups are significant components of the antioxidant defense in the plasma and are able to resist the oxidative propagation by inactivation processes of alkoxyl radicals ( $\left.\mathrm{RO}^{*}\right)$ and hydroxyl radical $\left(\mathrm{OH}^{*}\right)$ and the processing of these in alcohol or harmless water molecules.

$$
\begin{aligned}
& \text { protein }-\mathrm{SH}+\mathrm{RO}^{*} \longrightarrow \text { protein }-\mathrm{S}^{*}+\mathrm{ROH} \\
& \text { protein-SH }+\mathrm{HO}^{*} \longrightarrow \text { proteia }-\mathrm{S}^{*}+\mathrm{HOH}
\end{aligned}
$$

For their part thiil oxidized radicals react between them forming disulfide bonds 


$$
\text { protein }-\mathrm{S}^{*}+\text { protein }-\mathrm{S}^{*} \longrightarrow \text { protein }-\mathrm{S}-\mathrm{S}-\text { protein }
$$

Thus, thiol groups by of the own oxidation oppose to the attack of more toxic to tissues free radicals. Disulfide bonds newly formed can cause instability and alteration of protein molecules and their functions.

Tests for the determination of SH groups in plasma are based on the ability to develop a colored complex, the maximum measurable spectrophotometrically by absorbance at $412 \mathrm{~nm}$ after reaction with acid, 5,5-dithiobis-2-nitrobenzoic acid (DTNB) at room temperature.

DTNB normal range $370-450 \mu \mathrm{mol} / \mathrm{L}$. DTNB decreases in directly correlates with the decreased plasma antioxidant barrier efficiency achieved by thiol groups.

\section{Total antioxidants level assay}

It was conducted by monitoring biological sample ability to reduce iron - Free Radical Analytical System (FRAS). The technique is based on the principle of reduction method utilizing colorimetric tests related to redox responses using a slightly reduced oxidant in stoichiometric excess.

When the $p \mathrm{H}$ is low, the Felll-tripyridyl-s-triazine complex (Felll-TPTZ) is reduced to the ferrous form with the formation of a new complex. This complex has a measurable intense blue color with a maximum absorption of $593 \mathrm{~nm}$. The appearance of a positive reaction in these conditions, with a redox potential, will have the effect to reduce Felll-TPTZ complex. If we use an excess of Fe, the limiting factor of the -TPTZ Felll complex and the formation of color represent the reducing ability of the sample.

The method requires acetate buffer; 300mol/L, pH 3.6 tripiridil-S-triazine (TPTZ), $10 \mathrm{mmol} / \mathrm{L}$ (Sigma product) prepared in hydrochloric acid $\mathrm{HCl} 40 \mathrm{mmol} / \mathrm{L}$; ferric chloride $\mathrm{FeCl} 320 \mathrm{mmol} / \mathrm{L}$ from Fluka. 4 min reaction was monitored by measuring optical density at $593 \mathrm{~nm}$. Normal values are between $0.9-1.4 \mathrm{~mol} / \mathrm{mL}$.

\section{Results and discussions}

Most patients were aged between 61-70 years confirming the statistical data shows that over $80 \%$ of CRC occur in patients aged over 50 years (Figure 1).

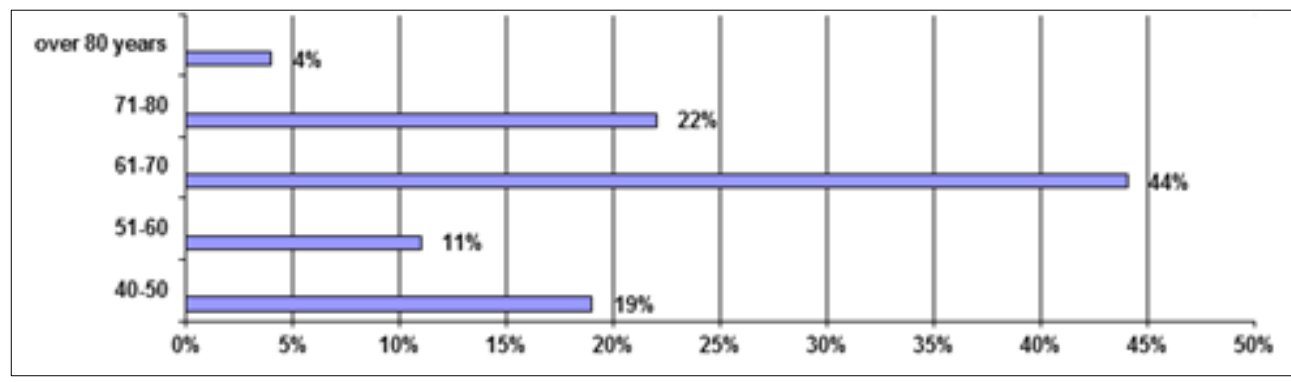

Figure 1. The distribution of patients by age

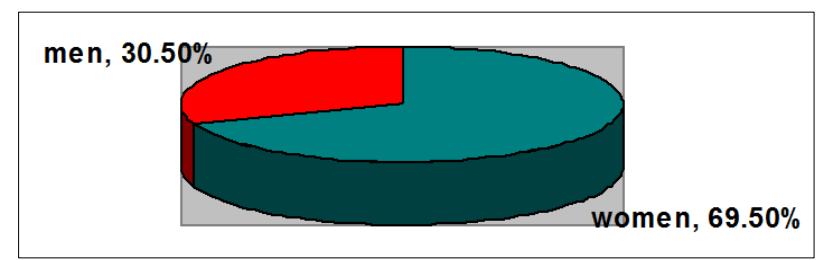

Figure 2. The distribution of patients by sex

The incidence of CCR is higher in women recorded data in our study are presented in the above chart (Figure 2). 


\section{Principles of oncology and Surgical procedure type}

Disease complications may include bleeding (20.24\%), occlusion (60.2 to 68.9\%), perforation with peritonitis (6.84 to $7.5 \%)$, perirectal suppurations $(6.20-6.73 \%)$ and invasion of neighboring organs (16-18\%) which impose partial resection or their excision, associated with the altered general behaviour of the patient, which raises other surgical technique issues (26-28). Since almost 2/3 of rectal cancers are hospitalized in advanced stages of disease with complications, loco-regional peritoneal invasion and decreased immunity, a proper assessment of the disease is mandatory and adopting an adjustment and appropriate therapeutic attitude (29).

Surgery still remains the most appropriate therapeutic modality in colo-rectal cancer. The immediate and at distance post-therapeutical prognosis is by consequence determined in good measure by the quality of the surgical act, by following the onco-surgical principles. The oncological radicality of surgery involves excision of the affected bowel segment range tumor segment and all lymphnode stations drainage (one to four); obtaining a safely free margins proximal, distal and lateral is very important. The surgical "no touch isolation" technique was practiced rutinely - primary approach of vascular pediculs to limit the mobilisation of tumoral cells in the vascular circuit, supra- and subtumoral enteral ligations to prevent the endolumenal distance nidation by the detachement of tumoral fragments and the isolation of the tumor with surgical draps during manipulation in order to not detach cells and tumoral residue that fixes intraperitoneally. All types of surgical resections in colorectal malignincy was performed. Duration of surgery was in the range 1-4 hours with individual variations; most of the operations lasted 2-4 h (Figure 3).

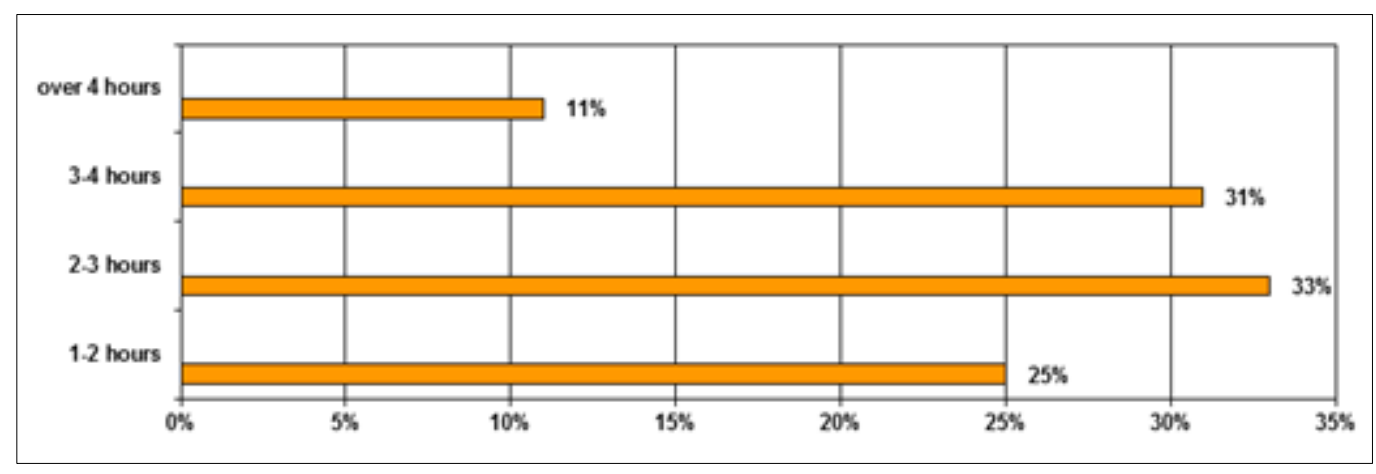

Figure 3. Duration of surgery

Surgical therapy for colorectal cancer is characterized by increased rates of morbidity and mortality. Prospective and retrospective evaluation from CRC surgery centers highlights rates of postoperative major morbidity ranging from 20 to 35 percent, with a mortality rate between 2-9 percent (30-33). A number of postoperative complications can be considered specific, some particularly serious, such as anastomotic leak, intraperitoneal hemorrhage, others with a modest clinical impact, such as wound infection.

In our study, complication rate during surgery are $13 \%$ of cases and fits into the above presented data.

The lipid peroxidation intensity expressed by the end product of lipid oxidative degradation decreases after surgery suggesting the involvement of reactive oxygen species in a higher proportion in the tumor tissue $(7.85 \pm 2.12 \mu \mathrm{mol} / 100 \mathrm{~mL}$ serum) than in its absence recorded after surgery $(6.98 \pm 1.37 \mu \mathrm{mol} / 100 \mathrm{~mL}$ serum) (Figure 4). 


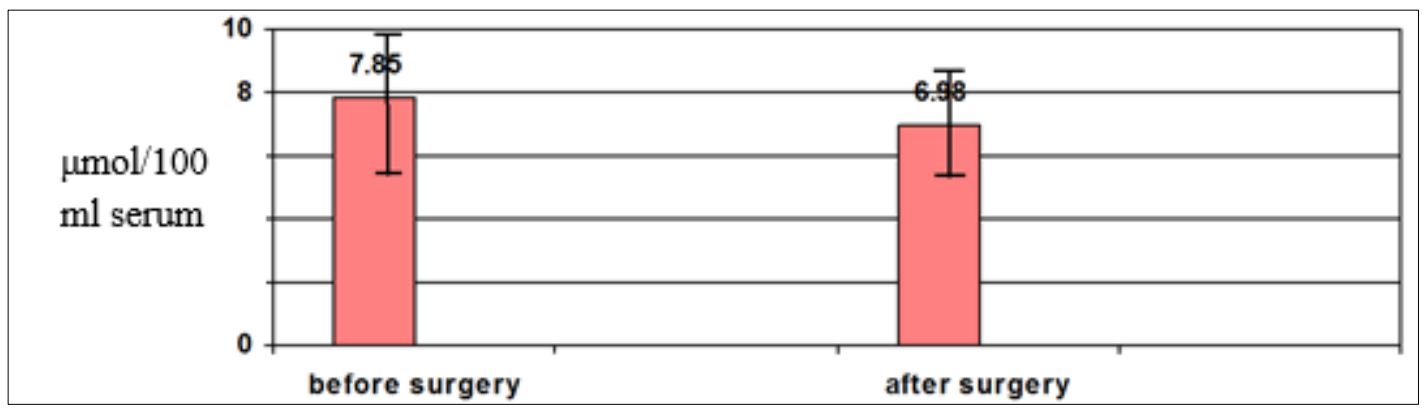

Figure 4. Plasma malondialdehyde (MDA) before and after surgery

Data from the literature confirm that ROS are involved in the process of lipid peroxidation. As a result, the elective target of oxidative stress are lipoproteins, due to their high content of polyunsaturated fatty acids, and lipid membranes. As an effect of lipid peroxidation, in the hydrophobic structure of polyunsaturated fatty acids a hydroperoxy group is placed, having as effect changes in the structural elements like lipoproteins and biomembranes. Specifically, the existing hydrophobic relationship between lipid-protein and lipid-lipid will be a malfunction one, with the appearance of some aldehyde derivatives and hydroperoxyl type radicals whose effect is a severe one at all levels of the cellular structures. Following the process of lipid peroxidation, there are a number of end products such as 4-hydroxynonenal or malondialdehyde, responsible for altering proteins following reaction with various groups like cysteine sulphydryl, lysine amino or histidine imidazole groups (34). A very good example is provided by 5-lipooxigenase, which at an enteral level plays an important role in biosynthesis and metabolism of lipid mediators of inflammation (leukotrienes), a group derived from arachidonic acid. Related to this mechanism, the hydroperoxides produced by catalytic process will decrease due to glithathione-peroxidase in patients with CRC before surgery and in those with tumor recurrence, when was detected a high level for lipid peroxidation derivatives in plasma (35). The phenomenon of lipid peroxidation is specific to patients with neoplastic disease, but the origin of the process is different depending on type and location of the cancer $(36,37)$. In CRC, lipid peroxidation is related with mitochondrial superoxide dismutase (SOD) activity. Therefore, it appears as logic the involvement of $\mathrm{OH} \bullet$ and $\mathrm{O} 2 \bullet-$, whereas the sum of add up to lipid peroxidation items are related with epithelial catalase expression, suggesting a $\mathrm{H} 2 \mathrm{O} 2$ - and/or OCl-mediated mechanism.

\section{CP (ceruloplasmin) before and after surgery}

It is well known that a number of metals such as copper, iron, selenium, zinc are essential components of the cell, both structurally and functionally, becoming part of various enzymes. Obviously, if their lack has a negative effect on cellular homeostasis, the excess presence leads to toxicity. Consequently, there must be a balance between intake, intracellular accumulation and use in association with protein chains to ensure cellular functionality and viability $(38,39)$.

High intracellular levels of these metals, such as copper or iron, have a toxic effect due to their ability to redox reactivity, as well as the involvement in ROS metabolism. As an example can be given, various complexes of $\mathrm{Cu}^{(\mathrm{II})}$ and $\mathrm{Fe}^{(\mathrm{II})}$ with low molecular weight can produce hydroxyl radical as a result of a reaction with hydrogen peroxide. Hydroxyl radical is currently considered the most aggressive form of ROS that can be found intracellularly. It should be noted that at the level of the neoplastic cell there is a disorder of redox function, the ability to regulate oxidative stress and in increased antioxidant capacity. Moderate growth of ROS is also thought to improve cell survival and proliferation capacity. Precisely, this ability for ROS to grow in tumor cells can be a key factor in carcinogenesis and could promote tumorigenesis. This increase in ROS level in the neoplastic cell forces these cells to the limit, very close to the critical point of toxicity. It seems obvious that, despite an increase in intrinsic antioxidant capacity, this level is not so high as to contain toxic ROS levels. 
Translated into a therapeutic formula, this reality of increasing oxidative stress in the neoplastic cell can be a good weapon in modern oncology (40-42).

This aspect was recorded and the obtained data on investigated patients namely ceruloplasmin activity, increased from $149 \pm 34$ to $154 \pm 10$ International Unit (IU) in response to increased lipid peroxidation (Figure 5). The endogenous antioxidant systems are signaling that participate in the mechanisms of removing tumor cells after surgical excision.

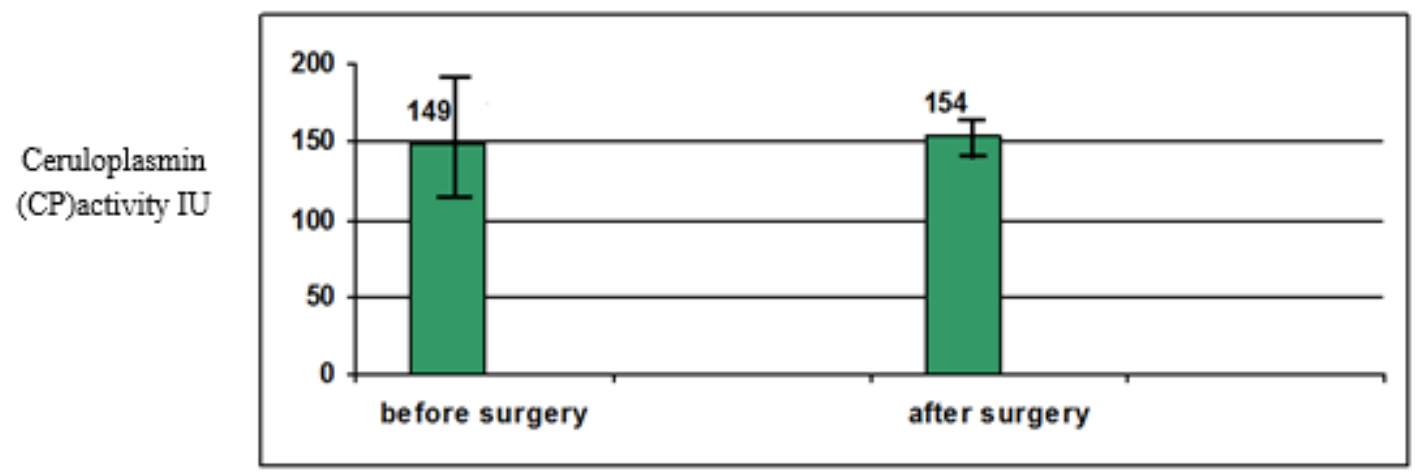

Figure 5. CP before and after surgery

\section{Thiol (-SH) group before and after surgery}

Among other things, the protein material is considered a favorite to ROS, a consequence of increased production of oxygen free radicals. Under their action, proteins undergo a process of structural oxidation as well as an inhibition of the proteolytic system. The main consequence is protein structural alteration and / or enzymatic dysfunction. Enzymatic dysfunction appears to have the most formidable consequences. A whole series of activities have to suffer, such as inactivation of DNA repair enzymes and loss of fidelity of damaged DNA polymerases in replicating DNA, increased/decreased uptake by cells, inhibition of enzymatic and binding activities. The degraded protein material enters in a catabolism process from which aminoacids will be obtained. The degree of oxidative damage of proteins is different and the resulting material has a different path. So, for proteins that have undergone a reduced oxidative process they are quickly selected and metabolized by the proteasome while severely oxidized proteins are a poor quality material, poor substrates for degradation and accumulate in cells. Accumulation over time at the cellular level of these degradation products is not without effect, such age-related pathologies. The incriminated mechanism is the inhibition of the proteaseome due to the accumulation of protein residues, having as effect the diminishing efficiency of metabolizing oxidized proteins, the increase of protein accumulations with structural defects and the dysfunction of the lysosomal system $(43,44)$.

The high level of thiol groups before surgery $(360 \pm 11 \mu \mathrm{mol} / \mathrm{L})$ and the decrease after the surgical procedure at $259 \pm 13 \mu \mathrm{mol} / \mathrm{L}$ in investigated patients suggest a oxidative stress given by tumor presence and its activity, which decrease after removal of malignant transformed tissue, and an endogenous antioxidant activity unbalanced by the excess production of reactive radical species (Figure 6.). 


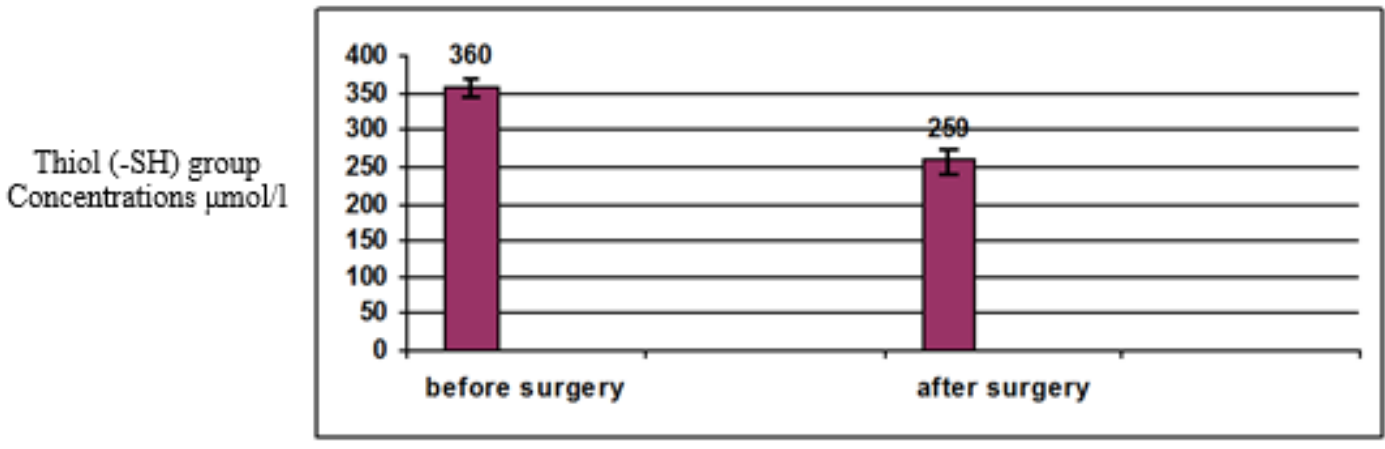

Figure 6. SH before and after surgery

However we look, one thing is clear: in the surrounding world, any living being is subjected to a greater or lesser stress challenges, having an effect on the mechanisms and the redox potential of the cells. This is probably why they need to developed numerous protecting mechanisms that give cells with a colossal capability of oxidoreduction homeostasis $(45,46)$.

The creation of an effective antioxidant defense system was based on several mechanisms that, although separate, work in a coordinated manner. The class of antioxidant compounds comprises three distinct classes. The first class consists of the following: catalase (CAT), superoxide dismutase (SOD), glutathione reductase (GR) and glutathione peroxidase (GPx). The second class gathers together various vitamins ( $\mathrm{C}, \mathrm{E}$, beta-carotene) and synthetic biological products like albumin, uric acid, bilirubin. The third class of products consists of degradation products due to the action of free radicals. An equally important role belongs to antioxidant micronutrients ( $\beta$-cryptoxanthin, $\alpha$ - and $\beta$-carotene, lutein, $\alpha$ - and $\gamma$-tocopherol, lycopene) that through their ability to repel free radicals will intervene in maintaining a redox homeostasis. As mentioned above, a good example is that of patients with adenomatous colonic polyps in whom the evaluation of the level of these antioxidant micronutrients in the colonic mucosa is at a low value compared to healthy subjects. Recent research on Selenium (Se), an important antioxidant micronutrient, has shown an important link between its presence/absence and the risk of CRC. The mechanism of action suggests that the Selenium level is the link that allows the crossing border of the adenomatous polyp to cancer (47-50). The same situation is valid for the measurable, in plasma, level of antioxidant enyzmes in patients with CRC, finding low values compared to the control group (vit. C, E). Concluding the above, we can strongly say that the failure of antioxidant protection mechanisms may be an important factor in the occurrence of colorectal cancer.

Consistent with the literature (51-55) the measured values of antioxidant capacity in serum are low in this category of patients before surgery demonstrating once again the installed oxidative stress in colorectal cancer patients (Figure 7). There is a dual relationship of cause-effect type between the tumor presence and the excess production of active metabolites of oxygen, but is hard to determine whether ROS are a reason or a result of the existence of malignant tissue.

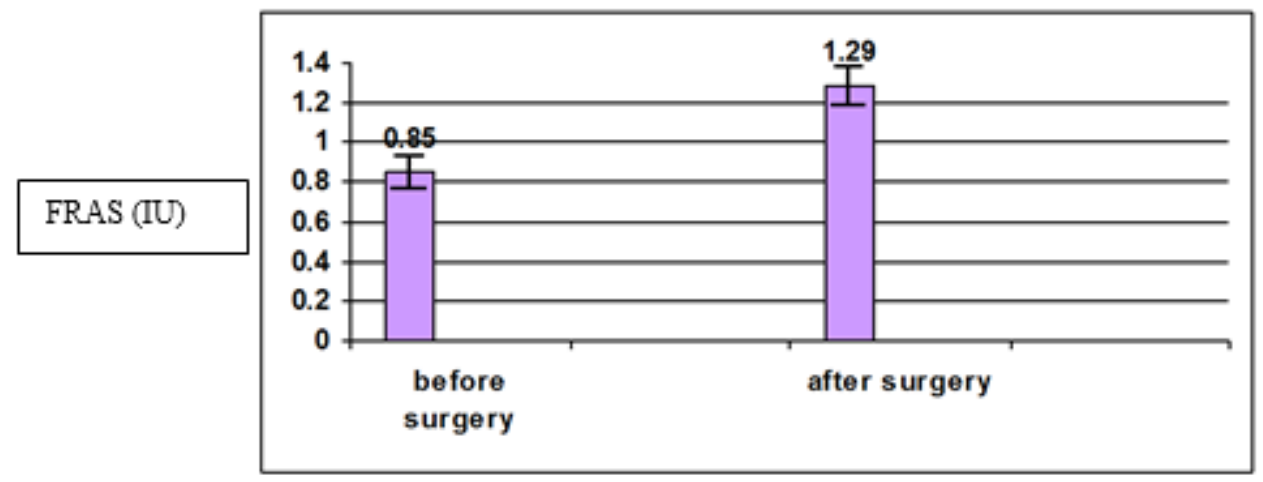

Figure 7. Free Radical Analytical System (FRAS) before and after surgery 


\section{Conclusions}

Tumor tissue induce reactive oxygen species in patients with colorectal cancer and a measurable oxidative stress using special techniques is available in biological samples.

The production of factors such as reactive oxygen species in homeostasis conditions is proportional to the level of use of the ROS by antioxidants enzyme-linked or not. At the tissue level, directly on the cell, there is a risk of injury as result of actions of ROS. Although ROS are indispensable elements for cellular function, intervening in the process of physiological oxygen metabolism, any inadequate variations in their level have undesirable effects. So, in conditions of sepsis, the decrease of ROS level is useful in the immune process of antimicrobial defense, or in the mitogenic response at the molecular level. Whenever, regardless of the circumstances, an excess of the ROS level is reported, either the protection mechanisms at the ROS are outdated or ineffective, oxidative stress occurs. The result of a persistent or excessive cellular oxidative stress is the initiation of an inflammatory response, with the appearance of lipid-protein defects, DNA alteration, the onset of apoptosis and the process of oncogenesis.

Surgical procedures by removing tumor tissue cause decrease of the oxidative stress, which is only temporal, future oncological treatments can again initiate active oxygen metabolism unbalancing.

Both, our study and others relatively similar, lead to the conclusion of the important role that ROS seems to play in the etio-pathogenic mechanisms of CRC. If the effects of oxidative stress have been partially elucidated, the same cannot be said about how to reach this situation. Can the cause be identified in decreased protection and / or local defense capacity or a failure of ROS metabolism, usually at the mitochondrial level? Difficult answer, at least for now. The production of ROS does not have an univocal mechanism. If we look in other directions, we can see other possible sources for the production of oxygen free radicals such as PMN infiltration or macrophage activation.

In conclusion, this multivalence of ROS production, regardless of the source or mechanism, is largely responsible for initiating oncogenesis and / or tumor behavior and aggression. Beyond explanations and understanding of the etiological mechanisms of CRC, starting as a consequence of oxidative stress, we will have to identify through research studies the role of anti-inflammatory and antioxidant protective processes in cell, how they are triggered and how they provide protection in cancer. So the natural question arises whether it is necessary to intervene with specifically antioxidative treatments and that is the time and the quantity to management them. As the information in these research programs will be processed and better understood, taking into account existing data, we can hope to identify specific targets for cancer therapy, particularly for CRC, which either limit the occurrence of ROS or increase the effect of antioxidant protection.

\section{References}

1.FERLAY J, COLOMBET M, SOERJOMATARAM I, MATHERS C, PARKIN DM, PIÑEROS M, ZNAOR A, BRAY F., Global and Regional Estimates of the Incidence and Mortality for 38 Cancers: GLOBOCAN 2018. Lyon: International Agency for Research on Cancer/World Health Organization; 2018.

2.***WORLD HEALTH ORGANIZATION. Global Health Observatory. Geneva: World Health Organization; 2018. who.int/gho/database/en/. Accessed June 21, 2018.

3.JUNG KW, WON YJ, KONG HJ, OH CM, LEE DH, LEE JS, Prediction of cancer incidence and mortality in Korea, Cancer Res Treat, 46, no. 2, 2014, p. 124-130, doi: 10.4143/crt.2014.46.2.124

4.BRAY F, COLOMBET M, MERY L, PIÑEROS M, ZNAOR A, ZANETTI R, FERLAY J, Cancer Incidence in Five Continents, Vol. XI (electronic version). Lyon: International Agency for Research on Cancer; 2017.

5.ARVELO F, SOJO F, COTTE C., Biology of colorectal cancer, Ecancermedicalscience, 9, no. 520, 2015, doi:10.3332/ecancer.2015.520 
6.BABAEI K, KHAKSAR R, ZEINALI T, HEMMATI H, BANDEGI A, SAMIDOUST P, ASHOOBI MT, HASHEMIAN H, DELPASAND $\quad$ K, TALEBINASAB $\quad$ F, NAEBI $\quad H$, MIRPOUR SH, KEYMORADZADEH A, NOROLLAHI SE, Epigenetic profiling of MUTYH, KLF6, WNT1 and KLF4 genes in carcinogenesis and tumorigenesis of colorectal cancer, Biomedicine (Taipei), 9, no. 4, 2019, doi:10.1051/bmdcn/2019090422

7.WATSON AJ, COLLINS PD, Colon cancer: a civilization disorder, Dig Dis., 29, no. 2, 2011, p. 222-228, doi: 10.1159/000323926

8.THIERY JP, ACLOQUE H, HUANG RY, NIETO MA, Epithelial-mesenchymal transitions in development and disease, Cell, 139, no.5, 2009, p. 871-90, doi: 10.1016/j.cell.2009.11.007

9.ROCHE J., Erratum: Roche, J. The Epithelial-to-Mesenchymal Transition in Cancer. Cancers, 2018, 10, 52. Cancers (Basel), Cancers (Basel), 10, no. 79, 2018, doi: 10.3390/cancers10030079

10.ZHU QC, GAO RY, WU W, QIN HL, Epithelial-mesenchymal transition and its role in the pathogenesis of colorectal cancer, Asian Pac J Cancer Prev., 14, no. 5, 2013, p. 2689-2698. doi: 10.7314/apjcp.2013.14.5.2689

11.MANNE U, SHANMUGAM C, KATKOORI VR, BUMPERS HL, GRIZZLE WE, Development and progression of colorectal neoplasia, Cancer Biomark, 9, no. 1-6, 2010, p. 235-265, doi:10.3233/ CBM-2011-0160

12.KASTRINOS F, SYNGAL S, Inherited colorectal cancer syndromes, Cancer J., 17, no. 6, 2011, p. 405-415, doi: 10.1097/PPO.0b013e318237e408

13.PANDURANGAN AK, DIVYA $\mathrm{T}$, KUMAR $\mathrm{K}$, DINESHBABU V, VELAVAN $\mathrm{B}$, SUDHANDIRAN G, Colorectal carcinogenesis: Insights into the cell death and signal transduction pathways: A review, World J Gastrointest Oncol., 10, no. 9, 2018, p 244-259, doi:10.4251/ wjgo.v10.i9.244

14.STJEPANOVIC N, MOREIRA L, CARNEIRO F, BALAGUER F, CERVANTES A, BALMAÑA J, MARTINELLI E, ESMO Guidelines Committee. Hereditary gastrointestinal cancers: ESMO Clinical Practice Guidelines for diagnosis, treatment and follow-up, Ann Oncol., 30, no. 10, 2019, p. 1558-1571, doi: 10.1093/annonc/mdz233

15.DICKINSON BC, CHANG CJ, Chemistry and biology of reactive oxygen species in signaling or stress responses, Nat Chem Biol., 7, no. 8, 2011, p. 504-511, doi: 10.1038/nchembio.607

16.CHIO IIC, TUVESON DA, ROS in Cancer: The Burning Question. Trends Mol Med., 23, no.5, 2017, p. 411-429. doi:10.1016/j.molmed.2017.03.004

17.ROMA PATEL, LINDSEY RINKER, JOANNA PENG and WILLIAM M. CHILIAN (December 20th 2017), Reactive Oxygen Species: The Good and the Bad, Reactive Oxygen Species (ROS) in Living Cells, CRISTIANA FILIP and ELENA ALBU, IntechOpen, DOI: 10.5772/intechopen.71547. Available from: https://www.intechopen.com/books/reactive-oxygen-species-ros-in-living-cells/ reactive-oxygen- species-the-good-and-the-bad

18.AFANAS'EV I., Reactive oxygen species signaling in cancer: comparison with aging. Aging Dis., 2,no.3, 2011, p.219-230.

19.SREEVALSAN S, SAFE S., Reactive Oxygen Species And Colorectal Cancer. Curr Colorectal Cancer Rep., 9, vol.4, 2013, p.350-357. doi:10.1007/s11888-013-0190-5

20.PETER PATLEVIC, JANKA VAŠKOVÁ, PAVOL ŠVORC, JR, LADISLAV VAŠKO, PAVOL ŠVORC, Reactive oxygen species and antioxidant defense in human gastrointestinal diseases, Integr Med Res., 5, vol. 4, 2016, p.250-258. Published online 2016 Jul 29. doi: 10.1016/j.imr.2016.07.004 21.ANTHONYTUBBS, ANDRÉ NUSSENZWEIG, Endogenous DNA Damage as a Source of Genomic Instability in Cancer (Review) Cell, 168, no. 4, 2017, p. 644-656, https://doi.org /10. 1016/j.cell.2017.01.002.

22.POETSCH, A.R., BOULTON, S.J., LUSCOMBE N.M., Genomic landscape of oxidative DNA damage and repair reveals regioselective protection from mutagenesis, Genome Biol, 19, no. 215, 2018. https://doi.org/10.1186/s13059-018-1582-2. 
23.AGGARWAL V, TULI HS, VAROL A., Role of Reactive Oxygen Species in Cancer Progression: Molecular Mechanisms and Recent Advancements, Biomolecules, 9, no.11, 2019, p. 735, doi:10.3390/biom9110735.

24.GÀO X., SCHÖTTKER B., Reduction-oxidation pathways involved in cancer development: a systematic review of literature reviews, Oncotarget, 8, 2017, p. 51888-51906. Retrieved from https://www.oncotarget.com/article/17128/text.

25.RAVIN R, NOMOTO S., Measurement of human serum ceruloplasmin by its $p$-phenylenediamine oxidase activity, Clin Chem, 16, 1970, p.903-910.

26.ZIELINSKI MD, MERCHEA A, HELLER SF, YOU YN., Emergency management of perforated colon cancers: how aggressive should we be? J Gastrointest Surg. 15, no. 12, 2011, p. 2232-2238. doi: 10.1007/s11605-011-1674-8

27.GUNNARSSON H, HOLM T, EKHOLM A, OLSSON LI., Emergency presentation of colon cancer is most frequent during summer, Colorectal Dis., 13, no. 6, 2011, p.663-668. doi: 10.1111/j.1463-1318.2010.02270.x

28.BARNETT A, CEDAR A, SIDDIQUI F, HERZIG D, FOWLKES E, THOMAS CR., Jr Colorectal cancer emergencies. J Gastrointest Cancer, 44, no.2, 2013, p. 132-142. doi: 10.1007/s12029-0129468-0.

29.SCHMOLL HJ, VAN CUTSEM E, STEIN A, VALENTINI V, ESMO Consensus Guidelines for management of patients with colon and rectal cancer. a personalized approach to clinical decision making. Ann Oncol., 23, no. 10, 2012, p. 2479-516. DOI: 10.1093/annonc/mds236.

30.KIRCHHOFF P, CLAVIEN PA, HAHNLOSER D., Complications in colorectal surgery: risk factors and preventive strategies. Patient Saf Surg., 4, no. 1, 2010, p. 5. Published 2010 Mar 25. doi:10.1186/1754-9493-4-5

31.RAGG JL, WATTERS DA, GUEST GD., Preoperative risk stratification for mortality and major morbidity in major colorectal surgery. Dis Colon Rectum, 52, 2009, p.1296.

32.JOCELYNE HÉBERT, SHERIF ELTONSY, JEFFREY GAUDET, CAROLINE JOSE, Incidence and risk factors for anastomotic bleeding in lower gastrointestinal surgery BMC Res Notes. 12, 2019, p. 378. Published online 2019 Jul 3. doi: 10.1186/s13104-019-4403-0

33.SLIEKER JC, KOMEN N, MANNAERTS GH, Long-term and perioperative corticosteroids in anastomotic leakage: a prospective study of 259 left-sided colorectal anastomoses. Arch Surg 147, 2012 , p. 447.

34.AFONSO CB, SPICKETT CM., Lipoproteins as targets and markers of lipoxidation. Redox Biol., 23, 2019, p.101066. doi: 10.1016/j.redox.2018.101066. Epub 2018 Dec 6. Review.

35.PIECHOTA-POLANCZYK A, FICHNA J., Review article: the role of oxidative stress in pathogenesis and treatment of inflammatory bowel diseases Naunyn Schmiedebergs Arch Pharmacol., 387, no.7, 2014, p. 605-20. doi: 10.1007/s00210-014-0985-1. Epub 2014 May 6.

36.PER ̌́E M., Oxidative stress in the pathogenesis of colorectal cancer: cause or consequence?, Biomed Res Int., 2013:725710. doi:10.1155/2013/725710.

37.JANION K, SZCZEPAŃSKA E, NOWAKOWSKA-ZAJDEL E, STRZELCZYK J, COPIJA A., Selected Oxidative Stress Markers in Colorectal Cancer Patients in Relation to Primary Tumor Location-A Preliminary Research. Medicina (Kaunas), 56, no.2, 2020, p. 47. Published 2020 Jan 21. doi:10.3390/medicina56020047.

38.IMAM MU, ZHANG S, MA J, WANG H, WANG F., Antioxidants Mediate Both Iron Homeostasis and Oxidative Stress. Nutrients, 9, no. 7, 2017, p. 671. Published 2017 Jun 28. doi:10.3390/nu9070671.

39.FORCINITI S, GRECO L, GRIZZI F, MALESCI A, LAGHI L., Iron Metabolism in Cancer Progression. Int J Mol Sci., 21, no.6, 2020, p. 2257. Published 2020 Mar 24. doi:10.3390/ijms 21062257.

40.TRACHOOTHAM D, ALEXANDRE J, HUANG P, Targeting cancer cells by ROS-mediated mechanisms: a radical therapeutic approach?, Nat Rev Drug Discov., 8, 2009, p.579-591. 
41.LIU C, CAO Y, CHENG Y, An open source and reduce expenditure ROS generation strategy for chemodynamic/photodynamic synergistic therapy. Nat Commun, 11, no.1, 2020, p. 1735. Published 2020 Apr 8. doi:10.1038/s41467-020-15591-4.

42.YANG B, CHEN Y, SHI J, Reactive Oxygen Species (ROS)-Based Nanomedicine, Chem Rev., 119, no.8, 2019, p. 4881-4985.

43.GUMENI S, EVANGELAKOU Z, GORGOULIS VG, TROUGAKOS IP., Proteome Stability as a Key Factor of Genome Integrity. Int J Mol Sci., 18, no.10, 2017, p. E2036. doi: 10.3390/ijms 18102036. Review.

44.AYALA A, MUÑOZ M.F.; ARGÜELLES S., Lipid Peroxidation: Production, Metabolism, and Signaling Mechanisms of Malondialdehyde and 4-Hydroxy-2-Nonenal. Oxidative Med. Cell. Longev., 1, 2014, p. 31.

45.ILARIA MARROCCO, FABIO ALTIERI , ILARIA PELUSO, Biomarkers of Oxidative Stress in Experimental Models and Human Studies with Nutraceuticals: Measurement, Interpretation, and Significance, Oxidative Medicine and Cellular Longevity, Volume 2017 |Article ID 6501046 | 32 pages | https://doi.org/10.1155/2017/6501046.

46.PREDESCU D, POPA B, GHEORGHE M, PREDESCU I, JINESCU G, BOERIU M, CONSTANTINOIU $\mathrm{S}$, The vascularization pattern of the colon and surgical decision in esophageal reconstruction with colon. A selective SMA and IMA arteriographic study. Chirurgia, 108, no.2, 2013, p. 161-71.

47.MÉPLAN C, HUGHES DJ, PARDINI B, Genetic variants in selenoprotein genes increase risk of colorectal cancer. Carcinogenesis, 31, no. 6, 2010, p.1074-1079.

48.LI Y, SEN A, REN J, ASKEW LM, SIDAHMED E, BRENNER DE, RUFFIN MT 4TH, TURGEON DK, DJURIC Z, Effects of vitamin E from supplements and diet on colonic $\alpha$ - and $\gamma$ tocopherol concentrations in persons at increased colon cancer risk. Nutr Cancer., 67, no. 1, 2015, p.73-81. doi:10.1080/01635581.2015.965333

49.FEDIRKO V, JENAB M, MÉPLAN C, Association of Selenoprotein and Selenium Pathway Genotypes with Risk of Colorectal Cancer and Interaction with Selenium Status. Nutrients, 11, no. 4, 2019, p. 935. Published 2019 Apr 25. doi:10.3390/nu11040935.

50.HUGHES DJ, FEDIRKO V, JENAB M, Selenium status is associated with colorectal cancer risk in the European prospective investigation of cancer and nutrition cohort. Int J Cancer, 136, no. 5, 2015, p.1149-61.

51.JIANG H, WANG H, DE RIDDER M., Targeting antioxidant enzymes as a radiosensitizing strategy. Cancer Lett., 438, 2018, p. 154-164. doi: 10.1016/j.canlet.2018.09.004. Epub 2018 Sep 14. Review

52.DHARMARAJA AT., Role of Reactive Oxygen Species (ROS) in Therapeutics and Drug Resistance in Cancer and Bacteria. J Med Chem., 60, no. 8, 2017, p. 3221-3240. doi: 10.1021/acs.jmedchem.6b01243. Epub 2017 Feb 14. Review

53.WANG K, JIANG J, LEI Y, ZHOU S, WEI Y, HUANG C., Targeting Metabolic-Redox Circuits for Cancer Therapy. Trends Biochem Sci., 44, no. 5, 2019, p. 401-414. doi: 10.1016 /j.tibs.2019. 01.001. Epub 2019 Jan 21. Review

54.ABDEL-DAIM, M.M., ZAKHARY, N.I., ALEYA, L., BUNGAU, S.G., BOHARA, R.A., SIDDIQI, N.J., Aging, metabolic, and degenerative disorders: Biomedical value of antioxidants, Oxid. Med. Cell. Longev., 2018, 2 pages. https://doi.org/10.1155/2018/2098123

55.GHEORGHE G., PANTEA STOIAN A., GAMAN M.A., SOCEA B., NEAGU T.P., STANESCU A.M.A., BRATU O.G., MISCHIAN D.L.D., SUCEVEANU A.I., DIACON C.C. The benefits and risks of antioxidant treatment in liver diseases, Rev Chim. 70, (2), 2019, 651-655.

$\overline{\text { Manuscript received: } 20.05 .2020}$ 